\title{
Using Peer Observation and Collaboration to Improve Teaching Practices
}

\author{
Erika Daniels ${ }^{1, *}$, Ron Pirayoff ${ }^{2}$, Steve Bessant $^{3}$ \\ ${ }^{1}$ School of Education, California State University San Marcos, San Marcos, CA 92096 USA \\ ${ }^{2}$ Oceanside Unified School District, Oceanside, CA 92058 USA \\ ${ }^{3}$ Oceanside Unified School District, Oceanside, CA 92057 USA \\ *Corresponding Author: edaniels@csusm.edu
}

Copyright (C) 2013 Horizon Research Publishing All rights reserved.

\begin{abstract}
The study examined whether and how teacher practice can be influenced when the existing research bases on best pedagogical practice and personal motivation were operationalized and then supported with opportunities for self-reflection. Administrators created a professional development experience, called Instruction Cadres, focused on peer observation and structured discussion around an essential question. Data from those discussions and observations suggested that creating environments supportive of analytic reflection and collaboration positively influenced teachers' attitudes toward their practice. Results highlighted the notion that analytic reflection can support teachers as they work toward intentionally improving their pedagogical practices. Structured conversations resulted in reflections on practice, suggestions for specific teaching strategies, revisions of the ways students were conceptualized.
\end{abstract}

Keywords Professional Development, Teacher Attitudes, Autonomy, Pedagogy

\section{Introduction}

Professional development experiences in K-12 education are often disconnected from what teachers actually want and need in order to authentically improve and/or strengthen their practice. Anecdotal experience suggests that they are rarely consulted about how they envision their on-going professional development manifesting itself. Instead, district and school administrators too frequently hire consultants or register for conferences based on perceived needs or state mandates. Empirical research shows a tendency to ask teachers to wait "passively" for a resolution rather than "proactively engaging the obstacles and participating in its remedy" (Glazer \& Hannafin, 2006, p. 180).

Because the teachers do not see a match between their needs and the services being offered, nor are they asked to engage in authentic reflection, there is limited usefulness in terms of actively improving their practice (Watts \& Lawson, 2009). Just as classroom curriculum requires teachers to differentiate their instruction to meet the needs of each student, professional development must be differentiated to meet the needs of individual teachers. Because of conflicting and myriad outside pressures, teachers are rarely given an opportunity to analyze their own practice and purposefully work to improve their specific areas of need (McCotter, 2001).

What to teach, how to teach, and how to reflect on one's practice are issues that ubiquitously challenge educators (Hunzicker, 2011). Creating professional development opportunities that have an authentic impact on practice depends on more than brief presentations (Hunzicker, 2011). Research indicates that motivation comes from within but is influenced by the contexts in which people live and work (Author, 2010) and heavily influenced by the degree of autonomy a person feels (Deci, Vallerand, Pelletier, \& Ryan, 1991). The more an individual has (or perceives he/she has) control over his actions and environment, the more likely he/she will be to engage in a task.

As research continues to show, the content in which individuals live and work influences the manner in which they function (Author, 2010; Gee, 1999). It therefore suggests the importance of being "practically critical" when thinking and talking about one's practice (Hagevik, Aydeniz, \& Rowell, 2012). Additionally, Glazer and Hannafin (2006) found that a collaborative apprenticeship model where teachers assume greater control over teaching and learning in their schools was essential in improving professional development practices.

Because teacher effectiveness is a determining factor whether or not students learn (Darling-Hammond, 2010) and because learners must be motived in order to achieve academic success, it is reasonable to assume that teachers' levels of autonomy will influence the quality of classroom practices. When teachers understand what specific pedagogical strategies contribute to effective learning, their students achieve more academically. Professional development can be structured to help educators construct 
and refine their understanding of how to support students' thinking and learning the most effective pedagogical practices (Borko, 2004).

The unique context of teaching means that teacher skills and knowledge are more important than nearly any other factor in predicting and determining students' academic success and thus development of teacher practice is essential (Darling-Hammond, 2010). One avenue is through intentionally thinking about curriculum and instruction and acting on that analysis(Capobianco \& Feldman, 2006). Whenteachers create meaning around their practice by engaging in critical reflection, professional growth is likely to occur (Capobianco \& Feldman, 2006).

This study examined whether and how teacher practice is influenced when the existing research bases on best pedagogical practice and motivation are operationalized and then supported with opportunities for self-reflection. In short, the researchers wanted to understand whether collaboration and peer observation could positively influence teachers' practice and attitude.

As educators across the globe wrestle with adjusting learning experiences to meet rapidly evolving societal and business expectations, the need to develop processes that support critical reflection and encourage growth in professional practice appears to be gaining urgency. Research into the efficacy of professional development in terms of positively improving pedagogical practices is promising and suggests that it can be used "as a lever for changing teacher practice" (Correnti, 2007, p. 262).

\section{Method}

\subsection{Context}

Two middle school principals in Southern Californiabelieved that professional development practices needed to become more targeted in order to better meet the needs of both students and teachers. The state of California identifies schools and districts as "Program Improvement" if annual test scores do not meet identified targets in a variety of areas, and the two schools in this study were designated as program improvement. Both principals sought to develop a culture of reflective questioning within their schoolsin order to strengthen professional conversations as a means to improving student learning.

Mandates from the state and district had driven most administrative decisions for close to a decade and focused primarily on creating programs and policies to address students who were not succeeding during the normal course of the school day. These policies emphasized after-school programs and other activities that occurred outside of the classroom while regular classroom instruction remained largely unexamined. The two leaders understood that student achievement was predicated on the quality of classroom teaching (Darling-Hammond, 2010), and their stated goal was to re-focus attention on what was actually happening inside of each classroom on a daily basis. Their plan for working toward this goal was to create groups of teachers who observed each other while teaching and then discussed those observations in a formalized setting using a structured conversation format. They called these groups Instruction Cadres.

\subsection{Participants}

At one middle school, the Instruction Cadres (ICs) were open to any teachers who wanted to participate. At the other middle school, the principal requested that the Science and English-Language Arts teachers participate because of theincreasing national focus on writing in all content areas as manifested in the Common Core State Standards.

In both schools, the teachers ranged in experience but typically had 10 years or more in the classroom. On-going, devastating budget cuts in California had caused a reduction in the number of new and early year teachers in most schools because state law required lay-offs to be conducted in reverse order of hire date. Each year early-career teachers were typically be the first to be laid off as budget cuts necessitated steadily increasing class sizes.Each IC participant felt comfortable in middle school, enjoyed middle school students, and had specific areas of practice that he/she intended to work on improving.

The principals identified an essential question, which was "How do we know that students are cognitively engaged and learning what we are teaching?"The question's intent was to emphasize student learning as the primary goal of schooling while still providing flexibility on what aspect of their practice the teachers wanted to focus. Each participant chose any area of practice on which to focus as long as it related to the essential question. Some chose areas of strength in order to refine and enhance them while others chose elements of their practice with which they struggled and with which they desired support from their colleagues. Typical focus areas included but were not limited to: transitions from one task to the next, quality and quantity of student talk during discussions, student behavior throughout a class period, and student understanding of higher-level concepts.

\subsection{Data Collection}

Each Instruction Cadre cycle consisted of three phases. During the first phase, all participants met to discuss the essential question: How do we know that students are cognitively engaged and learning what we are teaching? During that meting, they identified areas of focusspecifically related to their individual pedagogical goals and talked with their partner about logistics for phase two of the process. The second element consisted ofpeer observations during whichsubstitute teachers covered IC participants' classes and the partners observed each other and engaged in one-on-one debriefs about what they had seen in terms of each specific focus area. The third phase, a formal meeting with all participants, concluded the cycle. It was typically held at the 
end of the observation day in order to discuss the essential question through a structured conversation protocol from the Annenberg Institute for School Reform (Appendix A) using details from the observations as examples to describe emerging thinking and as evidence to support developing conclusions.

\subsection{Data Analysis and Interpretation}

Because the debrief discussions were typically 60 minutes in length, with some lasting as long as 90 minutes, rich data resulted from this process. The conversations were recorded digitally, and one researcher then transcribed them verbatim. These transcripts served two purposes: one focused onidentifying recommendations for teachers' immediate practice and the second purpose was to analyze data for the formalized portion of this research study. Transcripts were sent to the principals for use when planning next steps in their professional development agendas and were also analyzed with the intent of identifying themes that would guide a more global professional development direction for each principal.

The researcher read through transcripts looking for big and/or recurring ideas that indicated relationships between "human agency and social structure" (Charmaz, 2005, p. 508). By making comparisons between and among ideas stated throughout the debrief discussions, 27 initial categories or codes were identified. By identifying ways in which those categories informed, supported, or related to each other (Strauss \& Corbin, 1998), the primary researcher then named seven global themes of which four were most relevant to the question explored in this paper.

\section{Findings}

Analysis of the debrief discussions yielded codes and ultimately themes that are also reflected in the motivation research. The debrief conversations consisted of rich discussion about what the participants had seen in each other's classrooms and how specific teaching practices can and do influence students' academic work. The following sections describe the primary categories that arose out of the data anlaysis.

\subsection{Tenor of Debrief Conversations}

Participants made thoughtful insights, and the debrief discussions gained momentum as the teachers came to trust that the principals did not intend to use the ICs as an evaluative tool. When a participant identified a struggle or voiced a frustration, other members of the group engaged in problem solving around the concern, and the principals reiterated their appreciation for the teachers' willingness to think critically about their practice while seeking ways to optimize student learning.

Interestingly, each discussion appeared to follow a predictable pattern in terms of content. First,reflection on the usefulness of the IC process was ubiquitous. At least one participant began each debrief conversation with a statement about how the peer observation process provided a space for reflection that is frequently absent in a typical school day. Those reactions then gave way to a discussion of specific teaching practices; teachers remarking upon "good ideas" that they had witnessed or resolving to incorporate practices that had languished "in file cabinets" or resource books. The latter part of each discussion primarily focused on the teachers' attitudes about students, teaching, and learning. They fell into two distinct categories: 1) How teachers conceptualized the students, and 2) How to support learning in spite of the myriad challenges faced on a daily basis. The four prevailing themes with quotes illustrative of the tenor of that category are as follows:

- Reflections on practice and process: "When you are in someone else's room, you are watching the environment. I think things come to you differently. We can think about our strategies and our ways of delivering the content."

- Specific teaching practices: "We have file cabinets full of these great ideas, but we don't always use them. To see them in action was great."

- Conceptualizing students: "With Strategic classes, when the kids feel empowered, they are going to rise to the occasion. I think if we preface that at the beginning of the year with not just strategies but with acceptance . . then they know that we know where they are. They know it's okay and that we will work with them to help them build their skills. Sometimes it is having acceptance not only with who they are as learners but also with who they are."

- Ways to support learning: "They were engaged when it was lots of discussion. They were asking questions, volunteering, and showing that they understood at quite a deep level. Then you struggle with having them produce some kind of product."

\subsection{Teachers' Reflections on Current Practices}

The Instruction Cadres (ICs)created a reflective space for teachers. In the busyness of teaching content, monitoring learning, and interacting with hundreds of personalities on a daily basis, teachers often only reflect informally. Comments throughout each debrief session indicated that the IC process both allowed and encouraged teachers to carve out much-needed time for thinking critically about their practice. This reflection fell into two distinct categories: 1) Thinking about student learning and 2) Gaining confidence from colleagues.

Partly because the essential question (How do we know that our students are cognitively engaged and learning what we are teaching?) framed the teachers' initial thinking about the process, the discussion included statements like "Is 'on-task' the same as being cognitively engaged?" While many teachers commented about the need for students to be 
"on-task," the debriefs appeared to encourage intentional thinking about what that notion actually meant. Juan said, "You see them writing notes, but how do you know they are processing the material? What we were seeing the other person do became a reflection on us in terms of 'Okay, how do I manifest this good thing I'm seeing? Or how do I deal with this problem or challenge?" Juan's comment suggested that he (and others) were engaged in a process that not only encouraged them to think about whether students were learning but also to question whether and how they could modify their practice to enhance the student experience.

This thinking gave way to a more explicit appreciation of colleagues' practices. Marie reminded the group: "It helps to see teachers in action. You might know something is a great idea but to see it in action refreshes your energy about it." Erin elaborated by saying, "When I am standing and teaching, I am in a different space. Yes, I want the kids to be learning, and I'm thinking about that. When you are in someone else's room, though, you are watching the environment. I think things come to you differently. We can think about our strategies and ways of delivering content."

It was this "different space" that resonated with the majority of the participants because "everyone has that moment of realizing that the kids just didn't get it so you wonder if you are just talking to walls. Then you are in someone else's room, and you realize it happens. Sometimes kids don't get it, and sometimes they are awesome. Some lessons work, and some don't" (Brian). As the teachers were reminded that both their struggles and triumphs were not unique but were, in fact, shared by colleagues, their commitment to both the IC process and their own practice appeared to deepen. Jeff summarized by saying, "We were on task discussing not because we had to. We reinforced a lot of good techniques, which is the bottom line."

The IC participants also appreciated the opportunity to learn from each other. As Tanya said, "I am kind of a busy person, but I felt comfortable in T's room. It kind of gave me permission to let the kids just work on something. I think I get them riled up too much. There is too much going on sometimes." Rhonda's comment, "The expertise in this room and this school is amazing. We need to differentiate professional development and not assume that everyone is starting from the same place," summarized the teachers' attitudes and introduced the second primary theme that emerged from the IC process.

\subsection{Specific Teaching Practices}

Dominating each debrief conversation was a reaffirmation of the fact that what happens in the classroom on a daily basis matters tremendously. The IC participants were an effective teachers in their own right, and much of each session focused on curriculum and instruction as they explored ways to refine their practice: "I just like watching someone else teach for awhile because it not only triggers memories but also gives you ideas about what to do in the future" (Kathy).
One particular exchange between a Science and English-Language Arts (ELA) teacher emphasized the utility of cross-curricular connections. Science teacher: "I like knowing what Latin roots she is using so I can emphasize and reinforce them." ELA teacher: "Yes, when I was looking through the book, I saw that helio- was on our root list so the kids will hear me say that, and I can remind them that they heard it in Science class also.And also in Science they were talking about main idea and supporting detail, and the way they did it was this way ... We can support that too."

When the teachers realized or were validated in their thinking that each content area could and should support the others, the conversations gained energy. As Jesse said, "The other thing - at least with Science - there was a carryover. She was going over Latin roots. I don't know if she even realized it, but she used the Scientific method in teaching the steps of writing. That's what I picked up. She talked about a beginning and a body and conclusions, which is basically the Scientific method." These cross-curricular connections appeared to help the teachers feel less alone and more supported over the course of each school day.

In addition to being reminded of good ideas or about ways to make connections between and among various class periods, the Instruction Cadres encouraged teachers to reflect upon the growth that comes with experience. Robert: "I reflected on when I was a student teacher and a young teacher and remembered that I wasn't as organizationally sound as I am now. If you had walked into my classroom 30 years ago, you wouldn't have seen that. I've learned a lot over the years that is important in my class now." Or as Rebecca said, "I also think that each of us is organized. We have a plan, and we stick to the plan. I have to teach the concepts several different ways, and I think that is what comes from experience. I think it makes a difference because we have been around the block."Many teachers noted that their experience combined with the structure and embedded reflection of the ICs allowed them to be freer in implementing ideas gleaned from the observations and in making adjustments to their existing practice.

Specific pedagogical suggestions dominated each Instruction Cadre debrief. Mia said, "I saw the coolest thing in G's classroom. He has them set up in groups of 4, and they each have a letter. They would say things like, 'The number $1 \mathrm{~s}$ have this question; the number $2 \mathrm{~s}$ have this question, etc.' I know we've heard it said and seen it in our workshops, but I got to see it in practice. They were all engaged, and that was really good to see." Mia's observation revealed an alternative to the traditional jigsaw, and Natalie elaborated on the result of this approach. "They were taking pieces, re-crafting questions, putting answers together. It gave me an opportunity to see that learning isn't just done one way. They (the students) were working at their own pace, but they were all doing the work."

By using the IC debrief discussions as opportunities to problem solve without judgment or evaluation, the teachers began to feel more comfortable offering up their challenges for analysis. One exploration focused on the best ways to 
support their students' writing development as the students struggled to turn complex thoughts into coherent writing. Jeff said, "It was amazing to me that they all knew the concepts, and they all had 'what if' questions." The next step for him, however, was helping students turn those concepts into essays and reflections. Rebecca felt encouraged after her one-on-one debrief and shared his new strategies with the group: "What these guys suggested was chunks. I was trying to get the students to see how to chunk ideas, and both of my observers suggested having students do one idea and then write that chunk. Then go on to the next one and have them write that chunk instead of trying to give them the global all at once, which is usually my instinct."

While it may seem self-evident that specific teaching practices should dominate a conversation about instruction, it is not inevitable that this occurs. In fact, many teachers lamented the fact that much energy and many resources focus on initiatives designed to support struggling learners before and after the school day. By focusing instead on the instruction happening within the regular classroom and strategizing ways to strengthen that practice, teachers felt energized. They left each IC debrief with specific ideas to try in subsequent weeks and to analyze during their planning times.

\subsection{Conceptualizing Students}

Although political rhetoric can be rife with comparisons of teaching to business, medicine, or other industries, the IC participants illustrated how teaching and learning are unique phenomena that require negotiation among adult and student personalities as well as other contextual factors and thus require nuanced approaches to complex situations. One such factor, the manner in which teachers conceptualized their students, was brought into clear focus through the IC debriefs.

Many comments focused on the fact that the observations allowed teachers to view their students in new contexts, which meant they were interacting differently with each other or with the content. As George said, "In my room, I think the kids are learning the way I think they should be learning because I only see it through my own eyes. Then I walked into your room and saw that even though it was different, the kids were engaged and learning." While conversations in informal settings often revealed that students perform better, more poorly, or at least differently depending on the content of the class, the IC observations brought this reality into sharp relief. Laurie commented, "There are some kids where maybe one class isn't their strength. Then you see them with the other kids who may be more of a model. They don't give up. They see the kids looking back in the text or doing a pair/share so they work a little harder to get the information ... I had a lot of the same kids so it was interesting to see them not only in a different subject but also grouped differently."

Thinking about how students behaved differently with various teachers and students and in different content areas evolved into discussions about meeting the students where they are and working from that point. Mary said, "I had an opportunity to see some of my Intervention kids (students who were classified as being several years below grade level academically) in a regular class so it gave me an opportunity to go up to them and say, 'What do you need from me? What do you need me to do to help you access this?" Or as Jeff commented, "I noticed the kids in Q's room took chances. They had to volunteer, which is tough. It was an Intervention class and for me it was good to see." In addition to accepting the students as they are, Steve noticed that "there was a real difference in how you (another teacher) talked. She offered herself up as a model and did a think aloud of her thought process. There were so many opportunities for the kids to see how it's done and then opportunities for them to practice on their own." Finally, Dana summarized by saying, "It is important not to put students in a box because they can't do something. Use what they can do to help them learn what they can't."

In addition to all of the positive thinking in terms of conceptualizing the students as capable and willing, teachers also explored the notion of the "intentional non-learner," a term coined by one of the principals. "I can't make them value their education, and that's where I'm stuck. I feel like I'm beating my head against a rock (Carla)." Or as Grace said, "I am to the point where I am very frustrated. I am spending all of my time and energy on a few who aren't going to do anything no matter what I do."

As teachers became willing to explore their honest frustrations, the conversations provided a support and structure that allowed venting to give way to problem solving. They noticed that in certain classrooms "the mood was not just comfortable, but it was safe. What the kids said was validated." Evan attributed that mood to experience when he said, "There is a level of confidence that comes with experience, and veteran teachers are often more willing to take risks." The risks teachers referred to often included trusting students to make the right decisions even when all signs indicated otherwise.

The intentional non-learners in these teachers' classrooms had given up on their own academic success for myriad reasons. The Instruction Cadres facilitated a process by which teachers articulated long-held beliefs about students and then worked those beliefs into actions that would support learning. For example, Paula pointed out, "Sometimes you have one good day and two bad days. Then it's saying, 'Okay we're going to have a good day tomorrow.' It is recognition along the way; you are recognizing the little triumphs." This theme of recognizing small successes and meeting students where they are echoed throughout many of the IC debriefs.

Although it can be challenging to celebrate individual successes with class sizes of 35 or greater, the IC teachers came to a realization that that recognition was essential. "It is not lowering your expectations but maybe shrinking them. Baby steps are what you have to do. There are so many who are far behind, and we need to chunk expectations and celebrate with the kid" (Steve). Finally, some teachers 
reached a point during the process where they were comfortable asking for help. Myra's comment was representative of the feelings of many participants: "There are a lot of kids who have given up. They are set aside or they set themselves aside. I am not comfortable with that and would like to see that change. I'm not sure I have the tools to do that."

\subsection{Ways to Support Learning}

While the conversations during the IC debriefs wove between and among a variety of topics, the threads that ran through each were clear. The teachers were willing to reflect on the IC process itself, specific teaching practices, and how they conceptualized students. Each of these themes led to the fourth and final theme-understanding the most effective ways to support learning and foster cognitive engagement.

With large class sizes and an emphasis on standardized testing, compliant behavior is frequently the benchmark for measuring cognitive engagement. If students follow directions and do not cause disruptions, they are deemed to be "on task" and therefore engaged. The IC essential question asked teachers to critically analyze whether and how substantively their students were learning. In other words, were they cognitively and not just physically engaged? This led to a rich analysis of what students were thinking and how educators could help them move to develop more complex thought processes. Aaron said, "Sometimes my kids will give me the answer - a yes or a no-and I will say, "Explain that." They will say, "I can't." So then I say, "Well how do you know?" They will say because it's in the book." The IC teachers used the process to wrestle with ways to move their students beyond what is "in the book."

The primary line of thinking around fostering cognitive engagement was that modeling is essential. Margie explained, "The visual modeling is important; when you see someone who is actually turning pages, they say, 'Oh.' The physical engagement can lead to cognitive engagement." Karen said, "Another thing is the dialogue - they hear the other kids process the information, and the kids who are still working can say 'Okay.' There is clarification that goes on all the time. Or they can say, 'I was thinking that.' I think there is a lot to say about that kind of modeling."

The teachers recognized that modeling, both from peers and the teacher, led to greater proficiency in each content-area. Sometimes the improvement arose from understanding cross-curricular connections: "The confidence leads to autonomy, which helps the reluctant learner. If they know that a paragraph is the same in Social Studies, in Science, and even in Math, then that gives them confidence. That helps some of the reluctant learners want to engage. There's no magic answer for every kid, but something helps each" (Marion). Sometimes the proficiency led to more engaged students: "Once you achieve better outcomes, they are satisfied, and that's when you get the buy-in. When they feel that satisfaction, they are gratified. The total satisfaction by the student doesn't occur for awhile, and we have to bridge that gap" (Pat).

The important element of this theme was that the Instruction Cadre debriefs appeared to help teachers understand that they either already possessed the tools to support students' cognitive engagement or would be supported by administrators in obtaining those tools. Their students were capable of achieving academically but needed varying levels of support to do so. Chris summarized by saying, "We found that kids can understand the concepts and the big picture. It was the mechanics that held them up. If you can help them understand the big picture, it gives them entry into the more complex topics."

\section{Discussion and Implications}

Learning That Resulted Hagevik, Aydeniz, and Rowell (2012) asserted that supporting teachers in exploring "alternative solutions to teaching problems" (p. 677) requires contexts that encourage collaboration and communication. The ICs created those contexts by encouraging participants to move between and among celebrating successes, venting frustrations, and brainstorming solutions to challenges. A telling remark during one debrief session was "it just dawned on me" (Sally) in regards to a specific element of her teaching of writing. Many of the participating teachers reported that the process reminded them of practices that they knew were effective but that had disappeared from daily use for myriad reasons. Because the ICs created a space for critical refection with the specific goal of "actively improving practice" (Watts \& Lawson, 2009), the thinking that occurred had an immediate impact on instructional planning and delivery.

Principal support emerged an essential component of the IC experience. As the participants came to realize that both principals expected honesty in terms of teachers' challenges, the conversation became more substantive. Teachers focused less on hiding concerns and more on seeking viable solutions for on-going challenges. This outcome was foreshadowed by other research on the impact of principal leadership on teacher practice (Author, 2010, Carlisle \& Berebitsky, 2011). Thus a primary learning outcome from of this study was support for the notion that principals must be actively involved in their schools as instructional leaders, not merely administrators of budget and personnel.

Another essential learning was clarification around what effective professional development looks and sounds like. Desimone (2009) identified characteristics such as active learning and collective participation as being essential to professional development that substantively improves teacher practice. ICs operationalized both characteristics as they actively engaged teachers in thinking collectively about ways to grow their practice to better support student learning. The tenor of each debrief conversation was one of a collaborative commitment to build on strengths, address needs, and meet challenges.

\section{Concluding Remarks}


In order to support teacher growth and thereby positively impact student learning, the Instruction Cadres sought to provide a forum through which dedicated practitioners could thoughtfully analyze their practice. It has never been enough to make instructional decisions based solely on personal beliefs, but educators do provide the most effective instructional support for their students when they understand how personal beliefs are situated within both their professional experience and the academic research. By providing a non-evaluative context in which teachers and administrators talked about their practice, Instruction Cadres appeared to positively influence both teacher attitude and practice. Additionally, as the teachers engaged in intentional reflection, they began to articulate areas of their practice that would change and/or grow as a result of the process. This result was supported by other research suggesting that change occurs as teachers reflect on their practice (Ross \& Bruce, 2007). As motivated students rarely exist without motivated teachers, Instruction Cadres suggest a pathway to fostering both.

\section{REFERENCES}

[1] Borko, H. (2009). Professional development and teacher learning: Mapping the terrain. Educational Researcher, 33, 3-15.

[2] Capobianco, B., \& Feldman, A. (2006). Promoting quality for teacher action research: Lessons learned from science teachers' action research. Educational Action Research, 14(4), 497-512.

[3] Carlisle, J., \& Berebitsky, D. (2011). Literacy coaching as a component of professional development. Reading and Writing, 24, 773-800. DOE 10.1007/s11145-009-9224-4.

[4] Charmaz, K. (2005). Grounded theory in the 21st century: Applications for advancing social justice studies. The Sage Handbook of Qualitative Research, 3rd Edition. Thousand Oaks,CA: Sage Publications.
[5] Correnti, R. (2007). An empirical investigation of professional development effects on literacy instruction using daily logs. Educational Evaluation and Policy Analysis, $29,262-295$.

[6] Darling-Hammond, L. (2010). Soaring systems: High flyers all have equitable funding, shared curriculum, and quality teaching. American Educator, 34(4), 20-24.

[7] Deci, E., Valler and, R., Pelletier, L., \& Ryan, R. (1991). Extrinsic rewards and intrinsic motivation in education: Reconsidered once again. Review of Educational Research, 71(1), 1-26.

[8] Desimone, L. (2009). Improving impact studies of teachers' professional development: Toward better concepts and measures. Educational Researcher, 38, 181-199.

[9] Gee, J. (1999). An Introduction to Discourse Analysis: Theory and Method. London: Routledge.

[10] Glazer, E., \& Hannafin, M. (2006). The cooperative apprenticeship model: Situated professional development within school settings. Teaching and Teacher Education, 22, 179-193.

[11] Hagevik, R., Aydeniz, M., \& Rowell, C. G. (2012). Using action research in middle level teacher education to evaluate and deepen reflective practice. Teaching and Teacher Education, 28, 675-684.

[12] Hunzicker, J. (2011). Effective professional development for teachers: A checklist. Professional Development in Education, 37(2), 177-179.

[13] McCotter, S. (2001). Collaborative groups as professional development. Teaching and Teacher Education, 17(6), 685-704.

[14] Ross, J. A., \& Bruce, C. D. (2007). Teacher self-assessment: A mechanism for facilitating teacher professional growth. Teaching and Teacher Education, 23, 146-159.

[15] Strauss, A., \& Corbin, J. (1998). Basics of Qualitative Research: Grounded Theory Procedures and Techniques, 2nd Edition. Thousand Oaks, CA: Sage Publications.

[16] Watts, M., \& Lawson, M. (2009). Using a meta-analysis activity to make critical reflection explicit in teacher education. Teaching and Teacher Education, 25, 609-616. 